\title{
Response of the $5^{\prime}$-flanking region of the human 25-hydroxyvitamin D 1 1 -hydroxylase gene to physiological stimuli using a transgenic mouse model
}

\author{
I Hendrix ${ }^{1,2}$, P H Anderson ${ }^{1,2}$, J L Omdahl' ${ }^{3}$, B K May² and H A Morris ${ }^{1,2}$ \\ ${ }^{1}$ Hanson Institute, Frome Rd, Adelaide 5000, SA, Australia \\ ${ }^{2}$ School of Molecular and Medical Bioscience, University of Adelaide, Adelaide 5005, SA, Australia \\ ${ }^{3}$ Department of Biochemistry and Molecular Biology, University of New Mexico School of Medicine, Albuquerque, New Mexico 87131-5221, USA
}

(Requests for offprints should be addressed to H A Morris; Email: howard.morris@imvs.sa.gov.au)

\begin{abstract}
The enzyme 25-hydroxyvitamin D 1 $\alpha$-hydroxylase, or CYP27B1, is the key enzyme in the two-step activation process of vitamin $D$ to 1,25-dihydroxyvitamin $D(1,25 D)$. While a number of regulators of the renal CYP27B1 enzyme activity have been recognized for some years, their underlying molecular mechanisms remain largely unknown, and the DNA regions involved in the in vivo regulation of gene expression by these factors have not been delineated. We have generated a transgenic mouse line that expresses $1501 \mathrm{bp}$ of $5^{\prime}$ flanking region together with $44 \mathrm{bp}$ of $5^{\prime}$ untranslated region of the human CYP27B1 gene fused to the firefly luciferase reporter gene. Animals expressing the luciferase gene demonstrated that both luciferase protein and mRNA for CYP27B1 were localized to proximal convoluted tubule cells of the kidney. In 2-week-old animals, the expression of the transgene and the endogenous CYP27B1 mRNA levels in the kidney were highest and fell with increasing age. Both reporter gene expression and CYP27B1 mRNA levels were downregulated in response to increasing amounts of dietary calcium in a dose-dependent manner. Vitamin $D$ deficiency resulted in an increase in both the reporter gene and CYP27B1 expression. Interestingly, the increase in CYP27B1 mRNA levels was substantially higher than the increase in reporter gene expression, suggesting either that there is a post-transcriptional mechanism that increases the amount of CYP27B1 mRNA or that other regulatory elements are required to maximize the effect of vitamin D deficiency. These findings demonstrate that the 1501 bp $5^{\prime}$ flanking region of the CYP27B1 gene directs expression to the proximal convoluted tubules of the kidney and is responsible for increasing transcriptional activity when dietary calcium and vitamin $D$ levels are depleted. It also responds in the kidney to the physiological regulators of development and ageing.
\end{abstract}

Journal of Molecular Endocrinology (2005) 34, 237-245

\section{Introduction}

The mitochondrial cytochrome P450 enzyme, 25hydroxyvitamin D 1-hydroxylase (CYP27B1), is the rate-limiting enzyme that catalyses synthesis of the biologically active form of vitamin $\mathrm{D}, 1,25-$ dihydroxyvitamin $\mathrm{D}(1,25 \mathrm{D})$, which occurs through the hydroxylation of the precursor molecule 25hydroxyvitamin D (25D) (Omdahl et al. 2002, 2003). Expression of GYP27B1 was initially considered to be peculiar to the kidney, but subsequent work has demonstrated its presence in a number of extrarenal tissues where locally synthesized $1,25 \mathrm{D}$ can potentially act in a paracrine or autocrine fashion, modulating cell growth and differentiation and other physiological activities (Fu et al. 1997b, Jones et al. 1998, Hewison et al. 2000, Panda et al. 2001). By comparison, CYP27B1 expressed in the kidney is primarily responsible for the production of circulating $1,25 \mathrm{D}$, the hormone acting in a classical endocrine fashion to control calcium homeostasis in the body (Reichel 1989).

Expression of renal CYP27B1 is subject to tight regulation, and three important regulators identified are calcium ions, PTH (parathyroid hormone) and 1,25D itself (Feldman 1999, Murayama et al. 1999, Brenza \& DeLuca 2000). It is well recognized that during hypocalcemia an elevated serum PTH increases renal expression of CYP27B1 and hence 1,25D, resulting in increased absorption of calcium in the intestine (Feldman 1999). Additionally, there is evidence that calcium may play a more direct role in renal CYP27B1 expression, possibly through plasma membrane calcium receptor-directed mechanisms (Suda et al. 1973, Favus \& Langman 1986, Bland et al. 1999). The circulating level of $1,25 \mathrm{D}$ can act in an inhibitory fashion to lower renal CYP27B1 through a recently identified vitamin D receptor (VDR)-dependent mechanism in the $5^{\prime}$-flanking region of the CYP27B1 gene (Brenza \& DeLuca 2000, 
Murayama et al. 2004). Overproduction of 1,25D by the kidney is controlled by a separate mitochondrial cytochrome P450 enzyme, 25-hydroxyvitamin D 24hydroxylase (GYP24), the hydroxylase action of which results in inactivation of $1,25 \mathrm{D}$ (Omdahl et al. 2002). Because of the pivotal role of renal CYP27B1 in endocrine $1,25 \mathrm{D}$ synthesis, there is great interest in understanding the details of the molecular mechanisms that underlie the physiological responses of the CYP27B1 gene.

Animal experiments have shown that serum calcium and PTH levels can modulate CYP27B1 mRNA levels in the kidney (Matsumoto et al. 1987, Brenza \& DeLuca 2000), and experiments using transfected kidney cell cultures indicate responsiveness of the $5^{\prime}$-flanking region of the CYP27B1 gene to PTH (Gao et al. 2002). While these findings are compatible with transcriptional response mechanisms underlying the control of CYP27B1 expression in the kidney, it is unknown whether the $5^{\prime}$-flanking region of the gene can respond to such regulatory agents in vivo.

A transgenic mouse line that expresses a transgene comprising $1501 \mathrm{bp}$ of $5^{\prime}$-flanking region together with $44 \mathrm{bp}$ of $5^{\prime}$-untranslated region of the human CYP27B1 gene fused to the firefly luciferase reporter gene has been generated (pCYP27B1(-1501 bp)-Luc) (Hendrix et al. 2004). We now report the responses of luciferase expression in the kidney by this transgenic mouse line to the physiological challenges of ageing, dietary calcium and vitamin D status, and compare them to levels of endogenous CYP27B1 gene expression in the kidney as determined by mRNA quantification. In addition, the cellular location of expressed luciferase protein in the kidney has been compared with that of the endogenous GYP27B1 protein by an immunological approach.

\section{Materials and methods}

\section{Transgenic animals}

All pCYP27B1(-1501 bp)-Luc transgenic mice were male and female offspring of founder 2992, as described previously (Hendrix et al. 2004), and were bred at the Institute of Medical and Veterinary Science (Adelaide, Australia). The animals, which were raised to be vitamin D deficient, were bred from mothers fed a vitamin D-deficient diet and exposed to incandescent (UV-free) lighting. All other animals were exposed to standard fluorescent lighting with a 12-h light/dark cycle. The Institute of Medical and Veterinary Science ethics committee approved all animal procedures.

\section{Diet}

Mice were allowed to consume, ad libitum, tap water and either commercial chow, containing $1 \%$ calcium, $0 \cdot 6 \%$ phosphorus and $4000 \mathrm{U} / \mathrm{kg}$ vitamin D (Ridley AgriProducts Pty Ltd, Murray Bridge, Australia), or $8 \mathrm{~g}$ per day of AIN-93-VX semisynthetic diet (Reeves et al. 1993), with the levels of dietary calcium and vitamin D modified for the different experimental procedures.

\section{Effect of ageing}

pCYP27B1(-1501 bp)-Luc transgenic mice were killed at either $2,4,6,8,12$ or 64 weeks of age $(n=3)$. At the assigned age, animals were killed by cervical dislocation and both kidneys were removed. The kidneys from each animal were frozen, and homogenates prepared for analysis of luciferase activity and protein content, as described previously (Hendrix et al. 2004), and for RNA extraction and CYP27B1 mRNA analysis.

\section{Effect of dietary calcium and vitamin D manipulation}

The effect of dietary calcium on transgene expression and on endogenous CYP27B1 mRNA expression in the kidney was investigated in nine pCYP27B1(-1501 bp)Luc transgenic mice. All mice were maintained on a commercial chow diet and allowed tap water ad libitum until 12 weeks of age. Groups of three mice were allocated to one of three AIN-93-VX semisynthetic diets containing either $0 \%, 0.05 \%$ or $1.4 \%$ calcium (Reeves et al. 1993). All diets contained the recommended levels of vitamin D (AIN-93-VX; ICN Biomedicals Australasia, Seven Hills, Australia). At 16 weeks of age, mice were killed by cervical dislocation and both kidneys were removed for analysis of luciferase activity and CYP27B1 mRNA.

The effect of vitamin $\mathrm{D}$ deficiency was investigated in pCYP27B1(-1501 bp)-Luc transgenic offspring of dams fed an AIN-93-VX semisynthetic diet that contained $0 \cdot 1 \%$ calcium and no vitamin $\mathrm{D}$ (special vitamin $\mathrm{D}$ fortification mixture - vitamin D deficient; ICN Biomedicals Australasia), and maintained under incandescent (UV-free) lighting. Four vitamin D-deficient pups were raised on this vitamin $\mathrm{D}$-deficient diet and maintained under incandescent lighting until 12 weeks of age. The mice were killed and both kidneys were removed. From one kidney, homogenate was immediately prepared for analysis of luciferase activity and protein content. The second kidney was stored at $-70{ }^{\circ} \mathrm{C}$ until required for RNA extraction. In addition, blood was taken by cardiac puncture at the time of death. Serum 25D levels were measured in two, 10 -week-old littermates by ${ }^{125} \mathrm{I}$ radioimmunoassay (Immunodiagnostic Systems Ltd, Bolden, UK) to confirm vitamin D status.

\section{Measurement of luciferase activity}

Kidney tissue homogenates were centrifuged at 13000 r.p.m. for $5 \mathrm{~min}$ at $4{ }^{\circ} \mathrm{C}$, and firefly luciferase activity 
was measured in the supernatant in duplicate with a commercially available luciferase sssay system with reporter lysis buffer (Promega). A volume of $20 \mu \mathrm{l}$ supernatant was combined with $25 \mu$ l luciferase assay reagent (Promega), and the luminescence signal was measured with a TD 20/20 luminometer (Turner Design Instruments, Sunnyvale, CA, USA). All luciferase measurements were corrected for autoluminescence by subtracting the luminescence signal measured in a mixture of $20 \mu \mathrm{l}$ reporter lysis buffer and $25 \mu \mathrm{l}$ luciferase assay reagent.

\section{Analysis of endogenous gene expression}

Total RNA was extracted from kidneys with TRIzol reagent (Sigma), according to the manufacturer's instructions, and cDNA was generated as described previously (Anderson et al. 2003). The levels of endogenous CYP27B1 mRNA in the kidney were quantified with the ABI PRISM 7700 Sequence Detection System and software (Perkin-Elmer Applied Biosystems, Foster City, CA, USA). The sequences of the primers and probe were designed as previously described (Anderson et al. 2003), and were based on published sequences for mouse CYP27B1 cDNA (XM 125908) (Gene bank, PubMed). The sequences are as follows: forward primer, 5'cgtggcaggagagtttac 3 '; reverse primer, 5'ccaggcgegatccca3'; Taqman probe, 6 FAMttggcctagaaagtataggcgcgcggtgc-TAMRA. The level of endogenous CYP27B1 expression was expressed as CYP27B1 mRNA copy number per $\mu$ g of total RNA, as previously described (Anderson et al. 2003).

\section{Immunohistochemistry}

Sections from the frozen kidney of a 12-week-old, vitamin $\mathrm{D}$-deficient animal were cut to $5 \mu \mathrm{m}$. Thawed sections were fixed in acetone/methanol (50:50) for 4 min before incubation with 3\% horse serum (GRH Biosciences, Lenexa, KS, USA) for $30 \mathrm{~min}$ to reduce the background binding of antibody. Either the antiluciferase goat polyclonal antibody (1:5000) (Promega) or the antiCYP27B1 sheep polyclonal antibody (1:250) (kindly donated by Dr Martin Hewison, Division of Medical Sciences, Queen Elizabeth Hospital, Birmingham, UK) was added to the kidney sections and incubated overnight. Sections were subsequently incubated with a biotin-conjugated antigoat secondary antibody (Vector Laboratories, Burlingame, CA, USA) at a dilution of 1:250 for 30 min followed by a streptavidin-peroxidase conjugate (Pierce Biotechnology, Rockford, IL, USA) at a dilution of 1:1000 for $60 \mathrm{~min}$. Immunoreactivity was visualized by diaminobenzidine-hydrogen peroxide reaction. Sections were lightly counterstained with haematoxylin after the staining. Control experiments were performed by omission of the primary antibody.

\section{Statistical analysis}

One-way analysis of variance and Tukey's post-hoc tests were used to analyse the effects of ageing, dietary calcium and vitamin $\mathrm{D}$ on the luciferase activity and the endogenous CYP27B1 mRNA levels in kidney extracts. A value of $P<0.05$ was considered to be statistically significant.

\section{Results}

\section{Localization of promoter-directed luciferase protein and CYP27B1 protein}

The renal cellular locations of expressed luciferase protein and endogenous CYP27B1 protein were investigated by immunohistochemistry, using kidney slices from a vitamin D-deficient pCYP27B1(-1501 bp)Luc transgenic mouse. The presence of both luciferase and CYP27B1 protein was detected primarily in the proximal convoluted tubular cells of the kidney. Detection of proteins were not observed in the negative controls in which the antibodies were omitted (Fig. 1A and $\mathrm{B})$.

\section{Effect of age on transgene expression in the kidney}

Luciferase activity was the highest in total kidney extracts from 2-week-old animals and was significantly reduced at 4 weeks and 6 weeks of age $(P<0 \cdot 001)$ (Fig. 2A). Correspondingly, the levels of endogenous CYP27B1 mRNA closely followed a similar pattern with the highest level at 2 weeks of age, and with levels reducing significantly at 4 and 6 weeks of age $(P<0 \cdot 001)$ (Fig. 2B).

\section{Effect of dietary calcium on transgene expression in the kidney}

For this study, pCYP27B1(-1501 bp)-Luc transgenic mice maintained on commercial chow containing $1 \%$ calcium until 12 weeks were subsequently transferred to synthetic diets containing $0 \%, 0.05 \%$ and $1.4 \%$ calcium together with the recommended levels of vitamin D (Reeves et al. 1993). Both the levels of luciferase activity and endogenous CYP27B1 mRNA were highest in kidney extracts from mice fed the $0 \%$ calcium diet. In animals fed the $0 \cdot 05 \%$ and $1 \cdot 4 \%$ calcium diet, both the level of luciferase activity and endogenous mRNA levels were reduced (Fig. 3).

\section{Effect of vitamin D deficiency on gene expression in the kidney}

Vitamin D-deficient pups were obtained from pCYP27B1(-1501 bp)-Luc dams fed a diet containing 


\section{(A)}

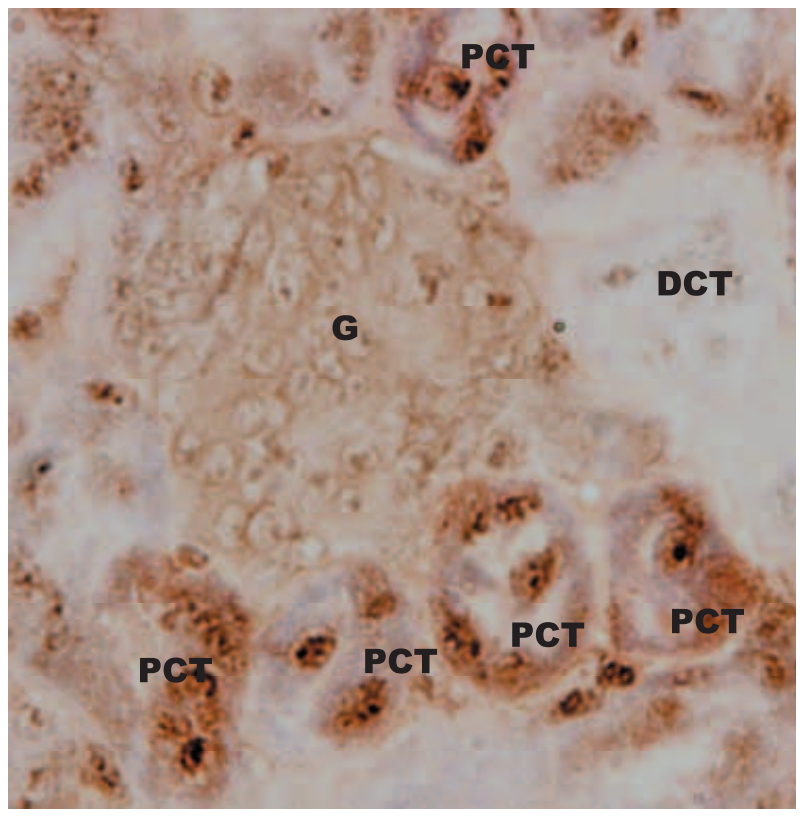

\section{(B)}

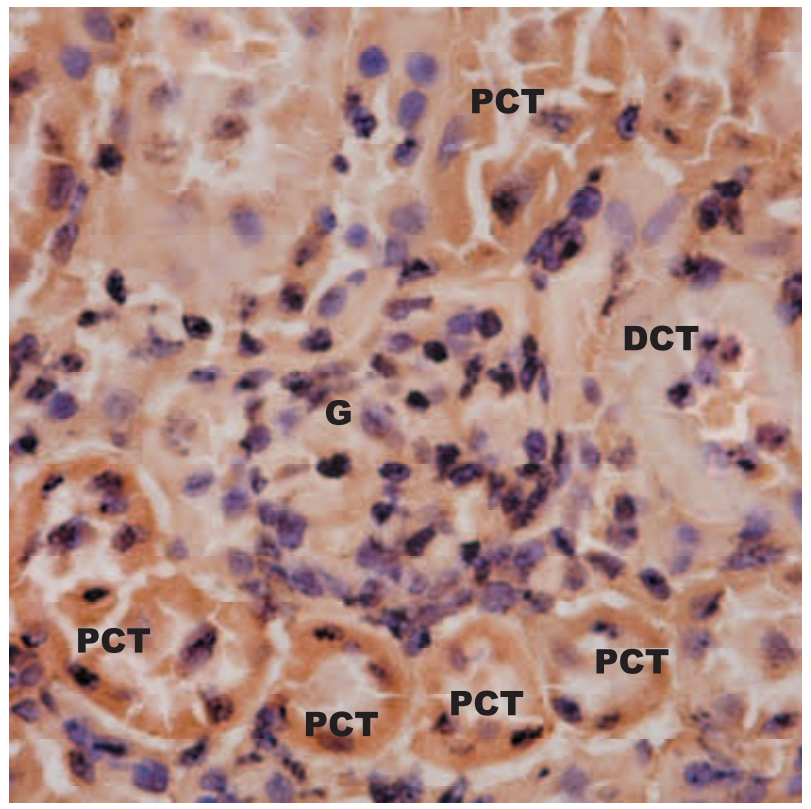

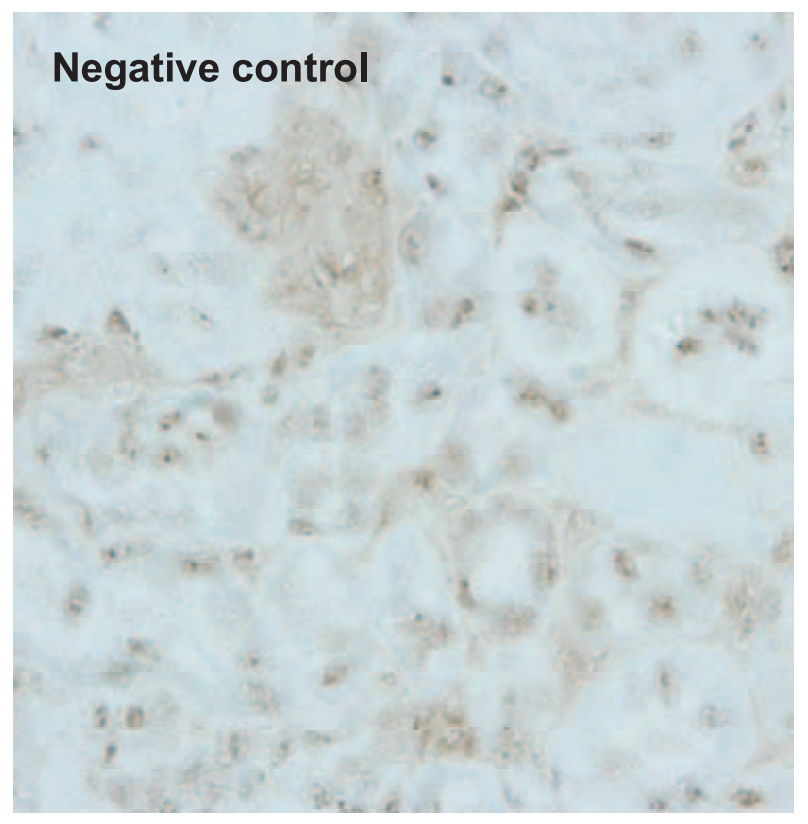

Figure $1 \mathrm{Immunohistochemical} \mathrm{analysis} \mathrm{of} \mathrm{the} \mathrm{expression} \mathrm{of} \mathrm{luciferase} \mathrm{protein} \mathrm{(A)} \mathrm{and} \mathrm{CYP27B1} \mathrm{protein} \mathrm{(B)} \mathrm{in} \mathrm{the} \mathrm{kidney} \mathrm{of} \mathrm{a}$ vitamin D-deplete pCYP27B1(-1501 bp)-Luc transgenic mouse. The negative control was performed by omission of the primary antibody. PCT, proximal convoluted tubule; DCT, distal convoluted tubule; G, glomerulus. Magnification: $\times 200$.

$0 \cdot 1 \%$ calcium and zero vitamin $\mathrm{D}$ while maintained under incandescent lighting. These pups were raised under similar conditions until 12 weeks of age. Serum 25D levels measured in two, 10-week-old littermates were 17.9 and $18.7 \mathrm{nmol} / \mathrm{l}$ respectively, indicating a significant reduction from levels obtained when fed a vitamin D-replete diet $(135 \pm 4 \mathrm{nmol} / \mathrm{l})$. Furthermore, the skeleton demonstrated evidence of osteomalacia in flexible, soft bones. It is suggested from these data and physical signs that the mice were sufficiently depleted of 
( $A$ )

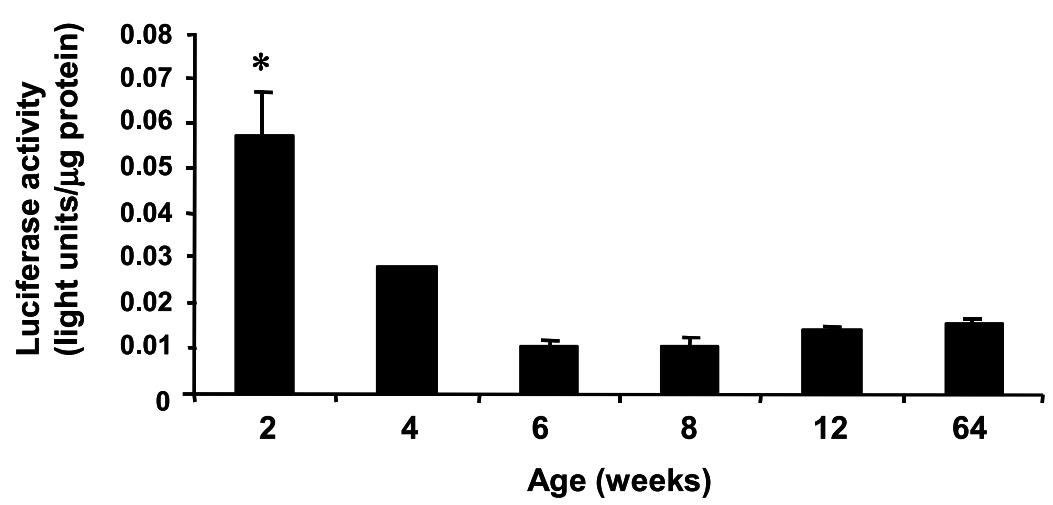

(B)

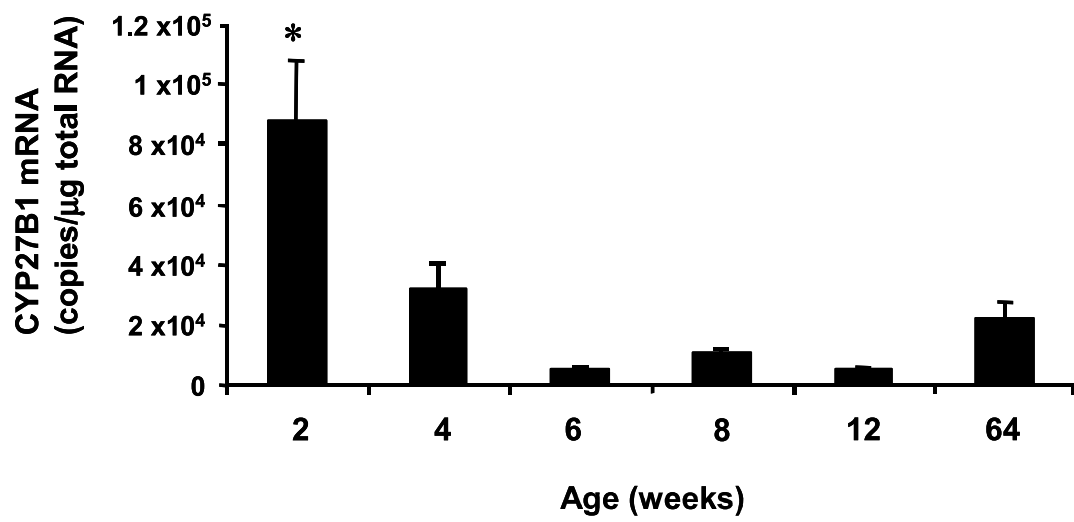

Figure 2 The effect of ageing on (A) the luciferase activity (light units $/ \mu \mathrm{g}$ of total protein) and on (B) the CYP27B1 mRNA levels (CYP27B1 mRNA copy number/ug of total RNA) in kidneys of pCYP27B1(-1501 bp)-Luc transgenic mice. * $P<0.001$ vs kidney samples from all age groups.

vitamin $\mathrm{D}$ and dietary calcium to induce secondary hyperparathyroidism and hypocalcaemia.

Analysis of the pCYP27B1(-1501 bp)-Luc transgenic offspring showed that in kidney extracts from the vitamin $\mathrm{D}$-depleted mice, luciferase activity was increased twofold $(P<0 \cdot 05)$ compared with animals on a vitamin D-replete diet (Fig. 4A). However, the level of GYP27B1 mRNA was markedly increased by 38 -fold $(P<0 \cdot 0001)$ in the vitamin D-depleted animals (Fig. 4B).

\section{Discussion}

We have established a transgenic mouse model that expresses the first $1501 \mathrm{bp}$ of $5^{\prime}$-flanking region of the human CYP27B1 gene fused to the firefly luciferase reporter gene. This transgene is widely expressed, with high levels in the testis, brain and kidney (Hendrix et al. 2004). The pattern of CYP27B1 promoter-directed tissue expression correlated closely with that reported in the literature for the endogenous CYP27B1 gene (Dusso et al. 1994, Fu et al. 1997b, Murayama et al. 1999, Panda et al. 2001). Hence, it appears that the 1501 bp promoter is sufficient to direct tissue-specific basal gene expression in such a way as to mimic endogenous CYP27B1 gene expression. We discuss whether this flanking region can respond in the kidney to physiological regulators known to be important for controlling renal CYP27B1 expression.

Immunohistochemical studies showed that both the expressed luciferase protein and endogenous CYP27B1 protein were colocalized to the proximal convoluted tubular cells in the kidney of the vitamin $\mathrm{D}$-depleted pCYP27B1(-1501)-Luc transgenic mice. This result confirms previous studies in which CYP27B1 mRNA was detected in the proximal convoluted tubules of both the fetal and adult kidney (Fu et al. 1997a, Zehnder et al. 1999, Panda et al. 2001, Zhang et al. 2002), 


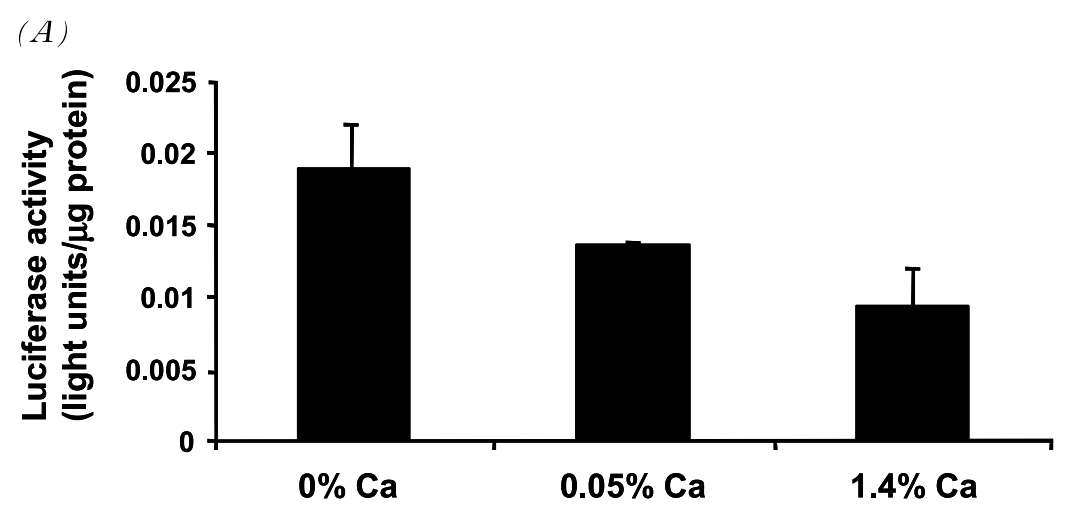

(B)

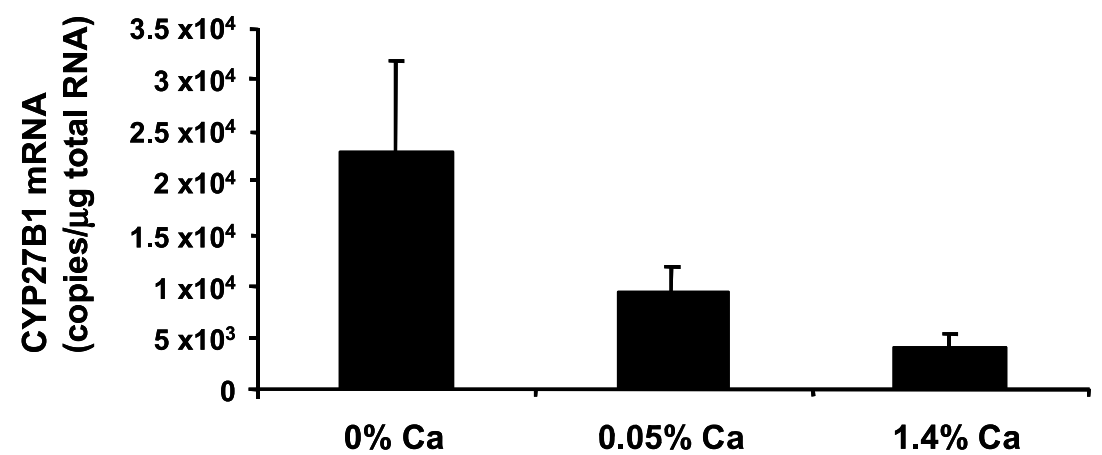

Figure 3 The effect of dietary calcium on $(A)$ the luciferase activity (light units/ $\mu \mathrm{g}$ of total protein) and on (B) the CYP27B1 mRNA levels (CYP27B1 mRNA copy number/ $\mathrm{gg}$ of total RNA) in kidneys of pCYP27B1(-1501 bp)-Luc transgenic mice.

demonstrating that the first $1501 \mathrm{bp}$ of the $5^{\prime}$-flanking region can direct transgene expression in the proximal convoluted tubules of the kidney in a manner consistent with that of the endogenous CYP27B1 gene.

During development and ageing of the pCYP27B1 $(-1501 \mathrm{bp})-\mathrm{Luc}$ transgenic mice, we observed that the level of luciferase activity in kidney extracts changed substantially. Activity was highest in the 2-week-old animals and was markedly reduced by about 6 weeks of age. A similar pattern was seen for endogenous CYP27B1 mRNA. The data are consistent with reported findings in both young rats and newborn infants that serum 1,25D and CYP27B1 enzyme activity levels are highest at this time and decline with increasing age (Ishida et al. 1987, 1988). High levels of circulating $1,25 \mathrm{D}$ are likely to reflect the increased need for calcium during this period of rapid growth and development. This concept is supported by the finding that the rachitic-like symptoms found after weaning in pups born to either VDR or CYP27B1 gene knockout dams can be corrected by feeding a rescue diet containing high levels of calcium and phosphate (Yoshizawa et al. 1997, Dardenne et al. 2003).
The significant observation in the current work is the strong correlation between the levels of age-dependent luciferase activity and endogenous CYP27B1 mRNA in the kidney. These data suggest that transcriptional regulatory actions, through response elements located within the $1501 \mathrm{bp}$ region of the CYP27B1 gene 5 -flanking region, play a significant role in the control of renal CYP27B1 expression during development. In transient transfection studies, we have previously identified functional transcription factor-binding sites in this 5'-flanking region that includes the $\mathrm{Spl}$ and Ets family of proteins (Gao et al. 2002). Such proteins could be important downstream targets for the actions of developmentally expressed hormones and growth factors.

When adult pCYP27B1(-1501)-Luc transgenic mice were fed a vitamin D-replete diet containing varying amounts of calcium, both the levels of luciferase activity and the renal CYP27B1 mRNA were reduced as dietary calcium increased in a dose-responsive manner. Hence, the effects of dietary calcium on renal expression of the CYP27B1 gene are mediated, at least in part, by responsive elements located within the -1501 bp region. 

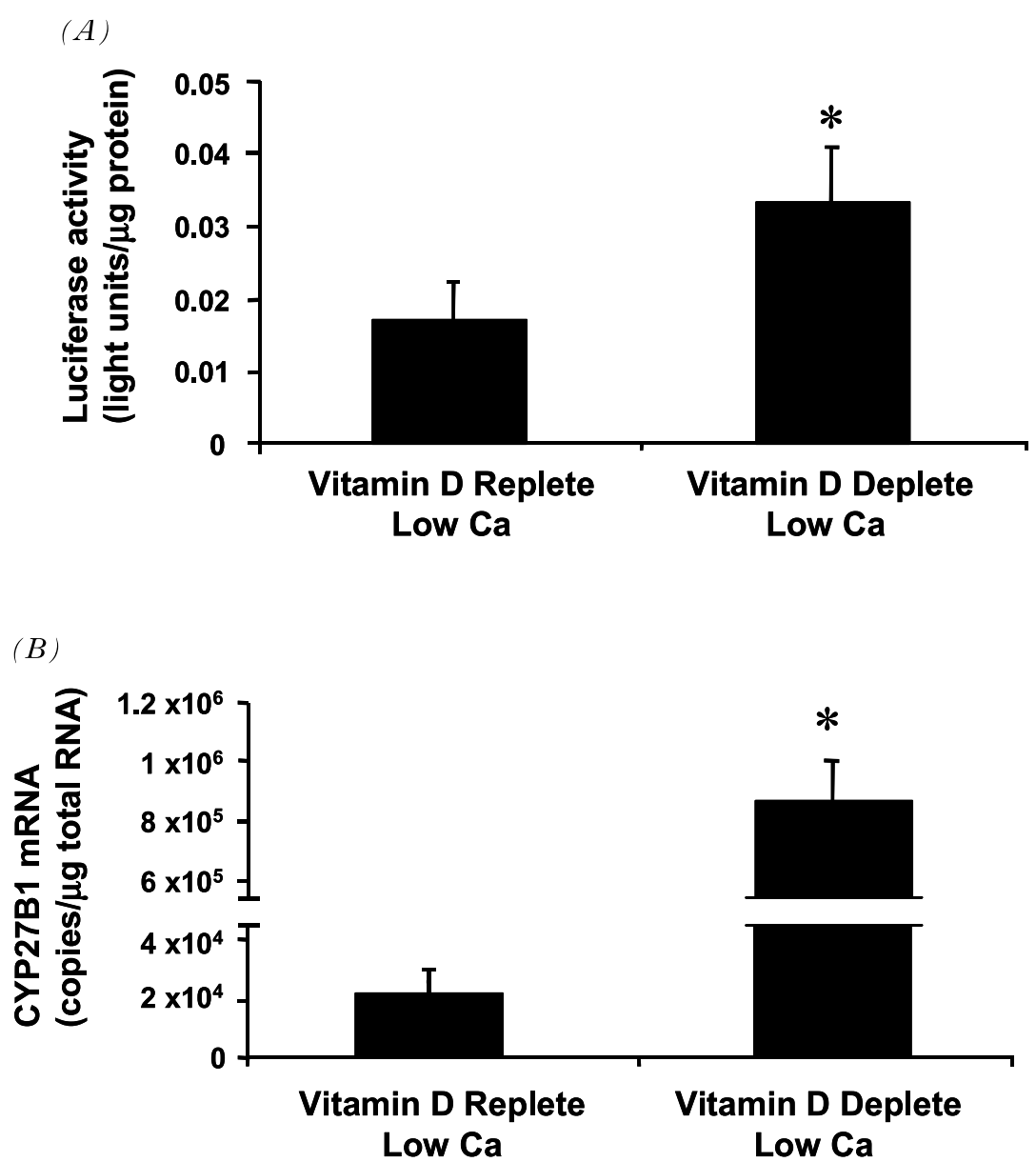

Figure 4 The effect of vitamin D deficiency on (A) luciferase activity (light units/ $\mu \mathrm{g}$ of total protein) and on (B) CYP27B1 mRNA levels (CYP27B1 mRNA copy number/ug of total RNA) in kidneys of pCYP27B1(-1501 bp)-Luc transgenic mice. ${ }^{*} P<0.05$ vs kidney samples from all age groups.

The highest level of luciferase expression occurred in animals fed a diet deficient in calcium. Previous studies in our laboratory have clearly shown that when rodents are fed a diet containing inadequate levels of calcium $(0 \cdot 1 \%)$, the levels of circulating PTH are significantly increased (O'Loughlin \& Morris 1998, Anderson et al. 2003). While a number of reports demonstrate that PTH and other agents that activate PKA signalling modulate transcription of the CYP27B1 gene, the molecular mechanism remains unclear (Brenza et al. 1998, Armbrecht et al. 2003, Murayama et al. 2004). Experiments using transfected kidney cells suggest that PTH may act through AP-1, CCAAT-box and E-box sites located in the proximal CYP27B1 promoter (Brenza et al. 1998, Gao et al. 2002, Murayama et al. 2004). In addition to the effect of increased PTH secretion, it is also possible that changes in circulating calcium levels may directly regulate CYP27B1 promoter activity through the renal calcium sensing receptor and downstream signalling pathways (Favus \& Langman 1986, Bland et al. 1999).

Both luciferase activity and CYP27B1 mRNA levels were increased in kidney extracts from pCYP27B1 $(-1501)$-Luc transgenic mice fed the low $(0 \cdot 1 \%)$ calcium, vitamin D-deplete diet compared with animals fed a zero-calcium, vitamin D-replete diet. This upregulation is consistent with results from a number of previous studies in which both renal CYP27B1 mRNA expression and enzyme activity are enhanced in response to vitamin D deficiency (Fox et al. 1991, Shinki et al. 1997, St-Arnaud et al. 1997). The resulting hypocalcaemia markedly upregulates serum PTH levels (Booth et al. 1985, Warner \& Tenenhouse 1985). Interestingly, we observed that while the renal CYP27B1 mRNA level increased by 38 -fold in response to vitamin $\mathrm{D}$ deficiency, the level of luciferase activity was elevated by only 
twofold. One possible explanation is that additional response elements located outside the $-1501 \mathrm{bp}$ region of the CYP27B1 gene, possibly in the upstream METTL1 gene or in an intron located within the CYP27B1 gene, are required for vitamin D deficiency to have its full effect on CYP27B1 gene expression in the kidney. An alternative possibility is that the very high level of endogenous CYP27B1 mRNA associated with vitamin D deficiency results from a PTH-mediated enhancement of mRNA stability. Such an effect would complement the known decrease in stability of the mRNA for CYP24 (Zierold et al. 2001).

The effect of dietary calcium per se on CYP27B1 mRNA levels in the kidney was relatively small when compared with the effects of age and vitamin D status. While the CYP27B1 mRNA levels were reduced by 15-fold during ageing and increased 38-fold during vitamin $\mathrm{D}$ deficiency, an increase in dietary calcium from $0 \%$ to $1 \cdot 4 \%$ decreased the CYP27B 1 mRNA expression by only fivefold. This finding is consistent with previous findings in our laboratory demonstrating a sixfold increase in CYP27B1 mRNA expression in kidney extracts from rats fed a $0 \cdot 05 \%$ calcium diet when compared with animals fed a $1 \%$ calcium diet (Anderson et al. 2003). The relatively small effect of dietary calcium on luciferase activity and the endogenous CYP27B1 mRNA expression in the kidney indicates that dietary calcium in the presence of adequate vitamin $\mathrm{D}$ is only a minor regulator of CYP27B1 expression in this tissue.

In summary, we show here that the $1501 \mathrm{bp}$ 5'-flanking region of the CYP27B1 gene directs expression to the proximal convoluted tubules of the kidney and upregulates transcriptional activity when dietary calcium and vitamin D levels are depleted. It also responds in the kidney to the physiological regulators of age and development. The work, therefore, establishes that these regulators result in altered transcriptional regulation of the gene in vivo. Additionally, we provide evidence that during vitamin $\mathrm{D}$ deficiency there is also a post-transcriptional mechanism that increases the amount of CYP27B1 mRNA, possibly through PTH action. In the future, it will be important to investigate further the role of PTH on renal CYP27B1 expression, particularly with regard to possible effects on mRNA stability.

\section{Acknowledgements}

We are grateful to the University of Adelaide for the support of an International Postgraduate Research Scholarship to $\mathrm{I} \mathrm{H}$, and to $\mathrm{Mr} \mathrm{J}$ Manavis for expert technical assistance with immunohistochemical techniques. The authors declare that there is no conflict of interest that would prejudice the impartiality of this scientific work.

\section{References}

Anderson PH, O'Loughlin PD, May BK \& Morris HA 2003 Quantification of mRNA for the vitamin D metabolizing enzymes CYP27B1 and CYP24 and vitamin D receptor in kidney using real-time reverse transcriptase-polymerase chain reaction. Fournal of Molecular Endocrinology 31 123-132.

Armbrecht HJ, Hodam TL \& Boltz MA 2003 Hormonal regulation of 25-hydroxyvitamin D3-1 alpha-hydroxylase and 24-hydroxylase gene transcription in opossum kidney cells. Archives of Biochemistry and Biophysics 409 298-304.

Bland R, Walker EA, Hughes SV, Stewart PM \& Hewison M 1999 Constitutive expression of 25-hydroxyvitamin D3-1 alpha-hydroxylase in a transformed human proximal tubule cell line: evidence for direct regulation of vitamin $\mathrm{D}$ metabolism by calcium. Endocrinology 140 2027-2034.

Booth BE, Tsai HC \& Morris RG Jr 1985 Vitamin D status regulates 25-hydroxyvitamin D3-1 alpha-hydroxylase and its responsiveness to parathyroid hormone in the chick. Fournal of Clinical Investigation 75 155-161.

Brenza HL \& DeLuca HF 2000 Regulation of 25-hydroxyvitamin D3 1 alpha-hydroxylase gene expression by parathyroid hormone and 1,25-dihydroxyvitamin D3. Archives of Biochemistry and Biophysics 381 143-152.

Brenza HL, Kimmel-Jehan C, Jehan F, Shinki T, Wakino S, Anazawa H, Suda T \& DeLuca HF 1998 Parathyroid hormone activation of the 25-hydroxyvitamin D3-1 alpha- hydroxylase gene promoter. PNAS 95 1387-1391.

Dardenne O, Prud'homme J, Hacking SA, Glorieux FH \& St-Arnaud R 2003 Connection of the abnormal mineral ion homeostasis with a high-calcium, high-phosphorous, high-lactose diet rescues the PDDR phenotype of mice deficient for the 25-hydroxyvitamin D-1 alpha-hydroxylase (CYP27B1). Bone 32 332-340.

Dusso A, Brown A \& Slatopolsky E 1994 Extrarenal production of calcitriol. Seminars in Nephrology 14 144-155.

Favus MJ \& Langman CB 1986 Evidence for calcium-dependent control of 1,25-dihydroxyvitamin D3 production by rat kidney proximal tubules. Fournal of Biological Chemistry 261 11224-11229.

Feldman D 1999 Vitamin D, parathyroid hormone, and calcium: a complex regulatory network. American Fournal of Medicine $\mathbf{1 0 7}$ 637-639.

Fox J, Kollenkirchen U \& Walters MR 1991 Deficiency of vitamin D metabolites directly stimulates renal 25-hydroxyvitamin D3-1-hydroxylase activity in rats. Metabolism $40438-441$.

Fu GK, Lin D, Zhang MY, Bikle DD, Shackleton CH, Miller WL \& Portale AA 1997 a Cloning of human 25-hydroxyvitamin D-1 alpha-hydroxylase and mutations causing vitamin D-dependent rickets type 1. Molecular Endocrinology 11 1961-1970.

Fu GK, Portale AA \& Miller WL $1997 b$ Complete structure of the human gene for the vitamin D 1 alpha-hydroxylase, P450c1 alpha. DNA and Cell Biology 16 1499-1507.

Gao XH, Dwivedi PP, Choe S, Alba F, Morris HA, Omdahl JL \& May BK 2002 Basal and parathyroid hormone induced expression of the human 25-hydroxyvitamin D 1 alpha-hydroxylase gene promoter in kidney AOK-B50 cells: role of Spl, Ets and CCAAT box protein binding sites. Internation fournal of Biochemistry and Cell Biology 34 921-930.

Hendrix I, Anderson PH, May BK \& Morris HA 2004 Regulation of gene expression by the CYP27B 1 promoter; study of a transgenic mouse model. Fournal of Steroid and Molecular Biology 89-90 139-142.

Hewison M, Zehnder D, Bland R \& Stewart PM 20001 alpha-Hydroxylase and the action of vitamin D. Fournal of Molecular Endocrinology 25 141-148.

Ishida M, Bulos B, Takamoto S \& Sacktor B 1987 Hydroxylation of 25-hydroxyvitamin D3 by renal mitochondria from rats of different ages. Endocrinology $121443-448$. 
Ishida M, Shima M \& Seino Y 1988 1,25(OH)2D and 24,25(OH)2D production in the developing kidney. Pediatric Nephrology 2 $166-170$.

Jones G, Strugnell SA \& DeLuca HF 1998 Current understanding of the molecular actions of vitamin D. Physiological Reviews 78 1193-1231.

Matsumoto T, Ikeda K, Morita K, Fukumoto S, Takahashi H \& Ogata E 1987 Blood $\mathrm{Ca}^{2+}$ modulates responsiveness of renal 25(OH)D3-1 alpha-hydroxylase to PTH in rats. American Fournal of Physiology 253 E503-507.

Murayama A, Takeyama K, Kitanaka S, Kodera Y, Kawaguchi Y, Hosoya T \& Kato S 1999 Positive and negative regulations of the renal 25-hydroxyvitamin D3 1 alpha-hydroxylase gene by parathyroid hormone, calcitonin, and 1 alpha,25(OH)2D3 in intact animals. Endocrinology $1402224-2231$.

Murayama A, Kim M-S, Yanagisawa J, Takeyama K-I \& Kato S 2004 Transrepression by a liganded nuclear receptor via a bHLH activator through co-regulator switching. EMBO $\mathcal{F} 23$ 1598-1608.

O'Loughlin PD \& Morris HA 1998 Oestrogen deficiency impairs intestinal calcium absorption in the rat. Fournal of Physiology 511 313-322.

Omdahl JL, Morris HA \& May BK 2002 Hydroxylase enzymes of the vitamin D pathway: expression, function, and regulation. Annual Review of Nutrition 22 139-166.

Omdahl JL, Bobrovnikova EV, Annalora A, Chen P \& Serda R 2003 Expression, structure-function, and molecular modeling of vitamin D P450s. Fournal of Cellular Biochemistry 88 356-362.

Panda DK, Al Kawas S, Seldin MF, Hendy GN \& Goltzman D 2001 25-hydroxyvitamin D 1 alpha-hydroxylase: structure of the mouse gene, chromosomal assignment, and developmental expression. Fournal of Bone and Mineral Research 16 46-56.

Reeves PG, Nielsen FH \& Fahey GG Jr 1993 AIN-93 purified diets for laboratory rodents: final report of the American Institute of Nutrition ad hoc writing committee on the reformulation of the AIN-76A rodent diet. Fournal of Nutrition 123 1939-1951.

Reichel H, Koeffler H \& Norman A 1989 The role of vitamin D endocrine system in health and disease. New England Fournal of Medicine 320 980-991.
Shinki T, Shimada H, Wakino S, Anazawa H, Hayashi M, Saruta T, DeLuca HF \& Suda T 1997 Cloning and expression of rat 25-hydroxyvitamin D3-1 alpha-hydroxylase cDNA. PNAS 94 $12920-12925$

St-Arnaud R, Messerlian S, Moir JM, Omdahl JL \& Glorieux FH 1997 The 25-hydroxyvitamin D 1-alpha-hydroxylase gene maps to the pseudovitamin D-deficiency rickets (PDDR) disease locus. Fournal of Bone and Mineral Research 12 1552-1559.

Suda T, Horiuchi N, Sasaki S, Ogata E \& Ezawa I 1973 Direct control by calcium of 25-hydroxycholecalciferol-1-hydroxylase activity in chick kidney mitochondria. Biochemical and Biophysical Research Communications 54 512-518.

Warner M \& Tenenhouse A 1985 Regulation of renal vitamin D hydroxylase activity in vitamin D deficient rats. Canadian fournal of Physiology and Pharmacology 63 978-982.

Yoshizawa T, Handa Y, Uematsu Y, Takeda S, Sekine K, Yoshihara Y, Kawakami T, Arioka K, Sato H, Uchimyama Y et al. 1997 Mice lacking vitamin D receptor exhibit impaired bone formation uterine hypoplasia and growth retardation after weaning. Nature Genetics 16 391-396.

Zehnder D, Bland R, Walker EA, Bradwell AR, Howie AJ, Hewison M \& Stewart PM 1999 Expression of 25-hydroxyvitamin D3-1 alpha-hydroxylase in the human kidney. Fournal of the American Society of Nephrology 10 2465-2473.

Zhang MY, Wang X, Wang JT, Compagnone NA, Mellon SH, Olson JL, Tenenhouse HS, Miller WL \& Portale AA 2002 Dietary phosphorus transcriptionally regulates 25-hydroxyvitamin D-1 alpha-hydroxylase gene expression in the proximal renal tubule. Endocrinology 143 587-595.

Zierold C, Mings JA \& DeLuca HF 2001 Parathyroid hormone regulates 25-hydroxyvitamin $\mathrm{D}(3)-24$-hydroxylase mRNA by altering its stability. PNAS 98 13572-13576.

Received 22 September 2004

Accepted 29 September 2004

Made available online as an Accepted Preprint

27 October 2004 